\title{
(iv) Managing bone loss of the femur and tibia in revision total knee arthroplasty
}

\author{
Glenn J. Kerr, M.D \\ The Rothman Institute at Thomas Jefferson University \\ Joseph A. Karam, M.D. \\ The Rothman Institute at Thomas Jefferson University \\ Javad Parvizi, M.D., FRCS \\ The Rothman Institute at Thomas Jefferson University
}

Follow this and additional works at: https://jdc.jefferson.edu/rothman_institute

Part of the Orthopedics Commons

Let us know how access to this document benefits you

\section{Recommended Citation}

Kerr, M.D, Glenn J.; Karam, M.D., Joseph A.; and Parvizi, M.D., FRCS, Javad, "(iv) Managing bone loss of the femur and tibia in revision total knee arthroplasty" (2012). Rothman Institute Faculty Papers. Paper 17.

https://jdc.jefferson.edu/rothman_institute/17

This Article is brought to you for free and open access by the Jefferson Digital Commons. The Jefferson Digital Commons is a service of Thomas Jefferson University's Center for Teaching and Learning (CTL). The Commons is a showcase for Jefferson books and journals, peer-reviewed scholarly publications, unique historical collections from the University archives, and teaching tools. The Jefferson Digital Commons allows researchers and interested readers anywhere in the world to learn about and keep up to date with Jefferson scholarship. This article has been accepted for inclusion in Rothman Institute Faculty Papers by an authorized administrator of the Jefferson Digital Commons. For more information, please contact: JeffersonDigitalCommons@jefferson.edu. 


\title{
As submitted to: \\ Orthopaedics and Trauma
}

And later published as:

\section{Managing Bone Loss of the Femur and Tibia in Revision Total Knee Arthroplasty}

\author{
Volume 26, Issue 2, April 2012, Pages 91-94 \\ DOI: 10.1016/j.mporth.2012.01.010
}
Glenn J. Kerr, M.D., Joseph A. Karam, M.D., Javad Parvizi, M.D., FRCS

Glenn J. Kerr, M.D.

Orthopaedic Fellow Adult Hip and Knee Reconstruction

The Rothman Institute at Thomas Jefferson University

925 Chestnut Street

Philadelphia, PA 19107

E-mail : Bachkerr1@gmail.com

Tel : +1 (215) 955-1500 (Office)

Fax : +1 (215) $503-5651$ (Office)

Joseph A. Karam, M.D.

Orthopaedic Research Fellow

The Rothman Institute at Thomas Jefferson University

925 Chestnut Street

Philadelphia, PA 19107

E-mail : joseph.karam@ rothmaninstitute.com

Tel : +1 (267) 339 - 3565 (Office) 


\author{
Fax : +1 (215) $503-5651$ (Office) \\ Javad Parvizi, M.D., FRCS \\ Professor of Orthopaedic Surgery \\ The Rothman Institute at Thomas Jefferson University \\ 925 Chestnut Street \\ Philadelphia, PA 19107 \\ E-mail : parvj@aol.com \\ Tel : +1 (267) $339-3572$ (Office) \\ Fax : +1 (215) $503-5651$ (Office)
}

\begin{abstract}
The number of primary and revision knee arthroplasty procedures performed yearly is steadily increasing. The management of bone loss at the time of revision surgery will play an integral role in the longevity and function of these knees into the future. There are a variety of options for addressing these defects varying from the use of polymethylmethacrylate bone cement, metal augments, sleeves, cones and large allograft replacements. This manuscript discusses the evaluation, classification and management of bone loss of the distal femur and proximal tibia.
\end{abstract}

\title{
KEY WORDS
}

Revision total knee arthroplasty, bone loss, metal augment, trabecular metal 


\section{INTRODUCTION}

Total knee arthroplasty (TKA) is one of the most successful adult surgical procedures performed in orthopedics today. The surgery has an acceptable complication rate and impressive clinical track records with high patient satisfaction ${ }^{1,2}$. An increasing number of arthroplasty procedures are performed in younger more active patients, with a proportional increase in the number and demand for revision surgery in the future. The revision burden is estimated to currently represent around $8 \%$ of total knee replacements and the demand for revision knee replacement is expected to grow by nearly $600 \%$ between 2005 and $2030^{3,4}$. Currently, the most frequent indication for total knee revision is periprosthetic joint infection, followed by mechanical loosening and then implant failure ${ }^{5}$. These technically demanding procedures can result in large amounts of bone loss during surgery, particularly while removing well fixed implants or following staged revision with a cement spacer ${ }^{6}$.

The surgeon's ability to address and deal with bony defects during surgery will have a direct impact on implant longevity and future revision surgeries. This chapter will deal with the fundamentals and strategies for addressing bone loss about the knee in the revision setting. The keys to successful 
outcome include appropriate pre-operative planning, minimizing bone loss during implant removal, restoration of the joint line and appropriate selection of bone augments and implants.

\section{PREOPERATIVE EVALUATION}

A thorough review of the patient's previous surgery or surgeries, including evaluation of the operative report and the time between implantation and failure, is crucial. Early onset of symptoms following surgery may represent mechanical issues related to alignment, rotation or possible infection. Any wound issues following the index surgery including prolonged drainage, need for antibiotic therapy or return to the operating room for manipulation or debridement should be noted. Revision implants with metaphyseal sleeves or trabecular metal cones may present particular difficulties during removal and greater degrees of bone loss should be anticipated.

Physical examination should include careful inspection of previous incisions, knee range of motion and stability as well as a neurovascular examination. Previous incisions should be noted and a plastic surgery consult is warranted for complex incisions, at risk skin bridges or if a previous soft tissue flap must be mobilized. Evaluation for venous stasis or arterial issues may warrant vascular consultation, particularly if pulses are not palpable on examination.

Preoperative imaging should include full length films from hip to ankle to evaluate alignment, dedicated anterior-posterior and lateral views of the knee, as well as sunrise and notch views. Expected bone loss is routinely underestimated, particularly on the lateral view of a posterior stabilized femoral component with a box ${ }^{7,8}$. Further quantification of rotational abnormalities and bone loss may be improved with computed tomography of the knee ${ }^{9}$.

Templating should be performed preoperatively using the planned implants and augments. This can also alert the surgeon to the need for large or structural grafts which can be 
ordered preoperatively. Stemmed implants are often required for revision cases and the canal width should be measured preoperatively.

Routine labs include a CRP, ESR to screen for infection and should also be obtained in all patients. Further workup for infection should performed if these values are elevated ${ }^{10}$

\section{CLASSIFICATION}

Several classification systems have been developed to assess bone loss in revision TKA. The most widely used one remains the Anderson Orthopeadic Research Institute (AORI) classification ${ }^{11}$. Bone defects are first classified based on preoperative $\mathrm{x}$-rays and then adjusted based on intraoperative findings. The femur and tibia are each classified separately into one of three types (Table1). Type 1 defects include intact metaphyseal bone with no compromise of implant stability. Type 2 defects involve bone loss in the metaphysis and are further subdivided based on whether one (type A) or both (type B) condyles are involved. In type 3 defects, a major portion of the condyle or plateau is affected, often compromising the origin or insertion of the collateral ligaments.

The Anderson classification may also assist the surgeon in implant selection. Type 1 defects are contained and may be addressed with simple cancellous bone grafting and primary components. Type 2 defects may require cement augmentation, metal augments or bone grafting to restore the joint-line. Type 3 defects may require structural bone grafting, metaphyseal sleeves or trabecular metal cones. Engh et al. have also identified specific radiographic landmarks that help classify bone loss by assessing their relationship to the implants ${ }^{11}$. The femoral epicondyles, posterior femoral condyles and location of the patella relative to the joint 
line are used for the assessment of femoral bone loss. The fibular head and tibial tubercle are used for the assessment of tibial defects.

Other classification systems have also been described, such as the Toronto classification by Clatworthy and Gross, which classifies bone defects as contained and uncontained ${ }^{12}$, and the University of Pennsylvania classification system, which is a quantitative classification system ${ }^{13}$.

[Insert Table 1 here]

\section{SURGICAL MANAGEMENT}

Surgical Exposure should incorporate old incisions and the most lateral incision should be used when possible to avoid skin necrosis. Short horizontal incisions may be crossed at right angles and dissection should proceed with elevation of full thickness flaps including skin and subcutaneous fascia ${ }^{14}$. A medial peri-patellar arthrotomy is preferred with care taken to avoid injury to the extensor mechanism.

Extraction of components is a crucial step in avoiding unnecessary bone loss. Specialized instruments should be available including thin flexible osteotomes, micro-blades and extraction tools for the femur and tibia. A burr and reverse curettes may be used for cement removal. Great care should be taken to avoid unnecessary perforation of the cortex. Minimal bone cuts are made about the femur, tibia and patella to remove fiborous tissue. The focus at this stage is on preserving the maximal amount of viable host bone and determining what may be necessary to reconstruct deficits. 
Addressing bone loss of the patella can be particularly challenging, especially in smaller patients with little residual bone stock. If the measured residual thickness is less than $11 \mathrm{~mm}$ then further resurfacing options are limited secondary to risk of fracture and extensor mechanism disruption. Alternatives include trabecular metal augments or bone grafting techniques ${ }^{15-17}$.

The true joint line should be established early to determine the amount of bone loss of the proximal tibia and distal femur. There are several reliable landmarks including the residual meniscal scar, one finger breadth $(10-12 \mathrm{~mm})$ below the inferior pole of the patella, $3 \mathrm{~cm}$ distal to the medial epicondyle or $2.5 \mathrm{~cm}$ distal to the lateral epicondyle. Once this is established, intramedullary reaming can be undertaken and provisional trials evaluated for the tibia and femur. The need for bone graft is indicated where there is inadequate support for the trial implants by host bone ${ }^{18}$.

The size and location of the bony deficit will dictate the type of augmentation and may limit implant choices. Smaller defects $<5 \mathrm{~mm}$ (AORI Type I) may be addressed with cement or cancellous bone chips ${ }^{19,20}$. Type II defects of the femoral condyles or tibial plateau can generally be addressed with metal augments attached to the implant ${ }^{21}$. These augments come in various sizes and are often used for distal femoral or posterior condylar bone loss (figure 1). They may be added in a symmetric or asymmetric fashion to both the femoral and tibial components.

[Insert Figure 1 here]

Larger contained defects involving the metaphysis of the femur or tibia can be addressed with metallic sleeves or trabecular metal cones. Sleeves are best suited for defects involving 
bone loss from medial to lateral with good anterior and posterior bone stock (figure 2). Larger trabecular metal cones can be used for areas of more significant bone loss. Uncontained defects of the condyles and plateau will require structural bone graft, particularly in younger patients ${ }^{22,}$ ${ }^{23}$. Engh has described an accepted technique utilizing femoral head allograft to reconstruct large condylar defects with good results. The merits and drawbacks of these techniques are outlined in table 2.

[Insert Figure 2 here]

[Insert Table 2 here]

Bony defects which compromise the collateral stability of the knee may dictate the use of constrained or possibly hinged implants. The surgeon should keep in mind that increasing degrees of constraint can lead to early aseptic loosening, particularly in younger and more active patients ${ }^{14}$. In the revision setting, stems should also be considered for both the tibia and femur when metal or allograft augments are used ${ }^{18}$.

A final consideration for graft augmentation is patient age and life expectancy ${ }^{18}$. Younger patients can be expected to place greater demands on implants, and future revisions should be anticipated. The use of autograft or allograft bone is more appealing in this patient demographic due to the potential for biologic incorporation and bone stock restoration ${ }^{23}$.

\section{FUTURE TRENDS}


Extensive research is still ongoing to identify graft options for larger bony defects in the revision setting. Ideal properties would include substitutes which behave mechanically similar to host bone, have a high rate of incorporation or interdigitation, allow immediate mobilization following surgery and avoid the risk of disease transmission. Trabecular metal and tantalum cones provide a favorable surface for osteoblast proliferation and integration, allow immediate weight bearing and carry no risk of disease transmission. Good short term outcomes with a very high rate of osseointegration have been reported, but future studies will be necessary to evaluate the long term outcome of these implants ${ }^{24-26}$. Revision of these cones may also be a major future issue, particularly in younger patients who are expected to have one or more revisions in their lifetime.

Research is also directed toward improving the stability of cancellous bone grafts by mixing allograft with stiffer constituents, such as ceramic or hydroxyapatite particles ${ }^{19}$. The clinical benefit of these composite grafts still has to be ascertained. Recombinant bone growth factors such as Bone Morphogenic Protein-2 (BMP-2) and BMP-7 (also known as Osteogenic Protein-1 or OP-1) have also been evaluated for reconstructive procedures. These proteins act to upregulate the differentiation of pluripotent mesenchymal cells leading to enhanced bone production. They may be used alone or in combination with bone grafts or bone substitutes ${ }^{27}$. Although these proteins have shown promising preclinical results, their clinical benefit in knee arthroplasty yet to be demonstrated in long term studies ${ }^{27}$.

\section{CONCLUSION}

Bone loss following total knee arthroplasty can be managed successfully with a wide variety of reconstruction methods. Methods such as autograft and allograft bone should be 
considered in younger patients to restore bone stock for future reconstructive procedures.

Smaller contained defects may be addressed with bone grafting, bone cement or metal augments.

Larger defects may require metaphyseal sleeves, trabecular metal cones or bulk allografts.

Intramedullary stems should be used in large defects involving the condyles or with questionable bone stock.

\section{REFERENCES}

1. Ethgen O, Bruyere O, Richy F, Dardennes C, Reginster JY. Health-related quality of life in total hip and total knee arthroplasty. A qualitative and systematic review of the literature. J Bone Joint Surg Am 2004 May;86-A(5):963-74.

2. Ackerman IN, Graves SE, Bennell KL, Osborne RH. Evaluating quality of life in hip and knee replacement: Psychometric properties of the World Health Organization Quality of Life short version instrument. Arthritis Rheum 2006 Aug 15;55(4):583-90.

3. Kurtz S, Mowat F, Ong K, Chan N, Lau E, Halpern M. Prevalence of primary and revision total hip and knee arthroplasty in the United States from 1990 through 2002. J Bone Joint Surg Am 2005 Jul;87(7):1487-97.

4. Kurtz S, Ong K, Lau E, Mowat F, Halpern M. Projections of primary and revision hip and knee arthroplasty in the United States from 2005 to 2030. The Journal of bone and joint surgery American volume $2007 \mathrm{Apr} ; 89(4): 780-5$.

5. Bozic KJ, Kurtz SM, Lau E, Ong K, Chiu V, Vail TP, et al. The epidemiology of revision total knee arthroplasty in the United States. Clin Orthop Relat Res Jan;468(1):45-51.

6. Calton TF, Fehring TK, Griffin WL. Bone loss associated with the use of spacer blocks in infected total knee arthroplasty. Clinical orthopaedics and related research 1997 Dec(345):148-54.

7. Bach CM, Biedermann R, Goebel G, Mayer E, Rachbauer F. Reproducible assessment of radiolucent lines in total knee arthroplasty. Clinical orthopaedics and related research 2005 $\operatorname{May}(434): 183-8$.

8. Nadaud MC, Fehring TK, Fehring K. Underestimation of osteolysis in posterior stabilized total knee arthroplasty. The Journal of arthroplasty 2004 Jan;19(1):110-5.

9. Lakstein D, Zarrabian M, Kosashvili Y, Safir O, Gross AE, Backstein D. Revision total knee arthroplasty for component malrotation is highly beneficial: a case control study. The Journal of arthroplasty 2010 Oct;25(7):1047-52.

10. Della Valle C, Parvizi J, Bauer TW, Dicesare PE, Evans RP, Segreti J, et al. Diagnosis of periprosthetic joint infections of the hip and knee. The Journal of the American Academy of Orthopaedic Surgeons 2010 Dec;18(12):760-70.

11. Engh GA, Ammeen DJ. Classification and preoperative radiographic evaluation: knee. Orthop Clin North Am 1998 Apr;29(2):205-17.

12. Clatworthy M, Gross AE. Management of Bony Defects in Revision Total Knee Joint Replacement. In: Callaghan JJ, Rosenberg AG, Rubash HE, Simonian PT, Wickiwicz TL, eds. The Adult Knee. Philadelphia, PA: Lippincott Williams \& Wilkins 2003:1455-64. 
13. Nelson CL, Lonner JH, Rand JA, Lotke PA. Strategies of stem fixation and the role of supplemental bone graft in revision total knee arthroplasty. J Bone Joint Surg Am 2003;85-A Suppl 1:S52-7.

14. Dennis DA. Wound complications in total knee arthroplasty. Instructional course lectures 1997; 46:165-9.

15. Tigani D, Trentani P, Trentani F, Andreoli I, Sabbioni G, Del Piccolo N. Trabecular metal patella in total knee arthroplasty with patella bone deficiency. The Knee 2009 Jan;16(1):46-9.

16. Nelson CL, Lonner JH, Lahiji A, Kim J, Lotke PA. Use of a trabecular metal patella for marked patella bone loss during revision total knee arthroplasty. The Journal of arthroplasty 2003 Oct;18(7 Suppl 1):37-41.

17. Hanssen AD. Bone-grafting for severe patellar bone loss during revision knee arthroplasty. The Journal of bone and joint surgery American volume 2001 Feb;83-A(2):171-6.

18. Cuckler JM. Bone loss in total knee arthroplasty: graft augment and options. The Journal of arthroplasty 2004 Jun;19(4 Suppl 1):56-8.

19. Whittaker JP, Dharmarajan R, Toms AD. The management of bone loss in revision total knee replacement. The Journal of bone and joint surgery British volume 2008 Aug;90(8):981-7.

20. Stulberg SD. Bone loss in revision total knee arthroplasty: graft options and adjuncts. The Journal of arthroplasty 2003 Apr;18(3 Suppl 1):48-50.

21. Dennis DA, Berry DJ, Engh G, Fehring T, MacDonald SJ, Rosenberg AG, et al. Revision total knee arthroplasty. The Journal of the American Academy of Orthopaedic Surgeons 2008 Aug;16(8):442-54.

22. Backstein D, Safir O, Gross A. Management of bone loss: structural grafts in revision total knee arthroplasty. Clinical orthopaedics and related research 2006 May;446:104-12.

23. Engh GA. Structural femoral head allografting with revision TKA. Orthopedics 2004 Sep;27(9):999-1000.

24. Meneghini RM, Lewallen DG, Hanssen AD. Use of porous tantalum metaphyseal cones for severe tibial bone loss during revision total knee replacement. J Bone Joint Surg Am 2008 Jan;90(1):78-84.

25. Long WJ, Scuderi GR. Porous tantalum cones for large metaphyseal tibial defects in revision total knee arthroplasty: a minimum 2-year follow-up. J Arthroplasty 2009 Oct;24(7):1086-92.

26. Lachiewicz PF, Bolognesi MP, Henderson RA, Soileau ES, Vail TP. Can Tantalum Cones Provide Fixation in Complex Revision Knee Arthroplasty? Clin Orthop Relat Res Apr 5.

27. Cook SD, Barrack RL, Patron LP, Salkeld SL. Osteogenic protein-1 in knee arthritis and arthroplasty. Clin Orthop Relat Res 2004 Nov(428):140-5. 